\title{
Implementasi Metode Importance-Performance Matrix Untuk Evaluasi Dan Peningkatan Pelayanan Perusahaan Jasa Care Cleaners
}

\author{
Ruli Utami ${ }^{*}$, Suryo Atmojo ${ }^{2}$ \\ 1, 2Institut Teknologi Adhi Tama Surabaya, ${ }^{2}$ Universitas Wijaya Putra \\ ruli.utami03@gmail.com*
}

\begin{abstract}
Abstrak
Kualitas merupakan tonggak utama dari industri bidang jasa, karena kualitas akan sangat mempengaruhi tingkat kepuasan dan loyalitas pelanggan terhadap konsumsi jasa yang di sediakan. "ABC" care cleaners merupakan franchise yang menyediakan layanan dan penyediaan jasa personal care dalam pencucian serta penyetrikaan pakaian. Untuk penentuan strategi pelayanan, maka di lakukan analisa terhadap loyalitas pelanggan (kepuasan), serta penilaian terhadap performa pelayanan perusahaan (kinerja). Analisa dilakukan pada sampling kuisioner terhadap 100 responden dengan materi 45 atribut atau variabel yang saling berpengaruh. Dari hasil pengolahan data menggunakan Importance-Performance Matrix, diperoleh nilai NIKi (importance) adalah sebesar 3.34 dan nilai NIKp (performance) sebesar 3.16. Hal ini menunjukkan bahwa pelanggan memiliki ekspektasi yang tinggi terhadap performa pelayanan perusahaan, sehingga harus ada perbaikan dan peningkatan pada variabel yang saling berpengaruh pada performa pelayanan. Dari hasil pemetaan diagram kartesius ImportancePerformance Matrix, diperoleh 6 variabel yang harus ditingkatkan kualitasnya pada "ABC" care cleaners. Sehingga peneliti mengusulkan beberapa langkah yang dapat diambil oleh manajemen sebagai upaya dalam peningkatan layanan terhadap pelanggan.
\end{abstract}

Kata kunci: IPM, Kualitas Jasa, NIKi, NIKp

\begin{abstract}
Quality is a major milestone of industrial services, because it will greatly affect the quality of the level of satisfaction and loyalty's customer for the consumption of services provided. "ABC" care leaners is Franchise that provide services and the provision of personal care services in the washing and ironing clothes. For the determination of service strategy, then do analysis on customer loyalty (satisfaction), as well as an assessment of the company's service performance (performance). The analysis was taken from sampling questionnaires to 100 respondents to the material 45 attributes or variables that affect each other. From the results of data processing using Importance-Performance Matrix, Niki's grade (importance) is at 3:34 and the value NIKp (performance) at 3:16. This indicates that customers have high expectations of the performance of the service companies, so some variables that affect the performance of each service should be improved. Cartesian diagram of the mapping of Importance-Performance Matrix, obtained 6 variables that should be improved on the "ABC" care cleaners. So, the researchers propose several steps could be taken by management as an effort to improve service to customers.
\end{abstract}

Keywords: IPM, Service's Quality, NIKi, NIKp

\section{Pendahuluan}

"ABC" care cleaners merupakan sebuah franchise yang berpusat di USA dan di bawah naungan sebuah perusahaan swasta di Indonesia sebagai pemegang lisensi. Sebagai perusahaan yang memproduksi jasa personal care sebagai produknya, "ABC" care cleaners yang menyediakan jasa dry cleaning and laundry, serta pressing only dituntut untuk menjaga kualitas kinerja agar loyalitas konsumen terjaga, dengan cara menentukan strategi yang tepat, yaitu dengan mempertahankan performa (kinerja) perusahaan dan kualitas layanan sesuai variabel yang berpengaruh pada kepuasan konsumen [1]. 
Perusahaan jasa merupakan perusahaan yang menjadikan pelayanan/jasa sebagai produk andalan (produk tidak berwujud), tujuan dari perusahaan adalah bagaimana dapat memenuhi apa yang dibutuhkan oleh konsumen sekaligus meningkatkan keuntungan secara materiel [2]. Untuk mencapai target keuntungan yang telah direncanakan, maka perusahaan dituntut untuk menjaga kualitas jasa yang merupakan bagian utama dari strategi perusahaan [3]. Dalam kualitas jasa, lima variabel utama yang digunakan sebagai variabel penelitian, yaitu:

1. Tangible, merupakan fasilitas fisik yang dapat dirasakan oleh konsumen secara langsung contohnya lahan parkir dan sarana komunikasi.

2. Realibility, merupakan akurasi layanan perusahaan dalam mendistribusikan jasa.

3. Reponsiveness, merupakan respons karyawan atas permintaan pelanggan dengan cepat dan tepat.

4. Assurance, merupakan rasa aman pelanggan yang dijamin oleh perusahaan.

5. Empathy, bagaimana perusahaan dalam memahami masalah pelanggannya dengan memberikan perhatian kepada pelanggan.

Sedangkan klasifikasi jasa dikelompokkan menjadi delapan jenis, yaitu [4]:

1. Segmen pasar, yaitu produk jasa hanya untuk end-user (misalnya asuransi jiwa atau pendidikan), dan jasa khusus konsumen organisasi (misalnya jasa konsultan).

2. Tingkat keberwujudan, yaitu keberadaan produk yang secara fisik bersinggungan dengan konsumen. Misalnya penyewaan mobil (ranted goods services), bengkel motor (owned goods services), jasa baby sitter (non-goods services).

3. Keterampilan penyediaan jasa, yaitu dalam menjalankan usaha jasa membutuhkan skill untuk menunjang aktivitas operasional sehingga loyalitas pelanggan dapat dipertahankan.

4. Tujuan organisasi jasa, dari tujuan organisasi jasa terbagi menjadi commercial services dan non-commercial services.

5. Regulasi, terdapat jasa yang operasionalnya harus sesuai ketetapan regulasi (misalnya bank) dan jasa yang tidak menjadikan peraturan sebagai sesuatu yang mengikat (misalnya catering).

6. Tingkat intensitas karyawan, yaitu equitment based service dan people based service.

7. Tingkat kontak (intensitas bertemu) penyedia jasa ada dua jenis jasa, yaitu high-contact service (misal rumah sakit) dan low-contact service (misal jasa pos).

Importance-Performance Matrix merupakan metode yang biasa diimplementasikan untuk mengetahui variabel pelayanan yang berpengaruh besar terhadap seberapa tingkat kepuasan dan loyalitas pelanggan, serta variabel pelayanan yang perlu ditingkatkan kinerjanya dikarenakan ada ketidaksesuaian dengan persepsi pelanggan terhadap produk yang ditawarkan perusahaan [5]. Faktor kepentingan maupun tingkat kinerja kemudian akan digabungkan dalam sebuah grafik dua dimensi seperti pada Gambar 1.

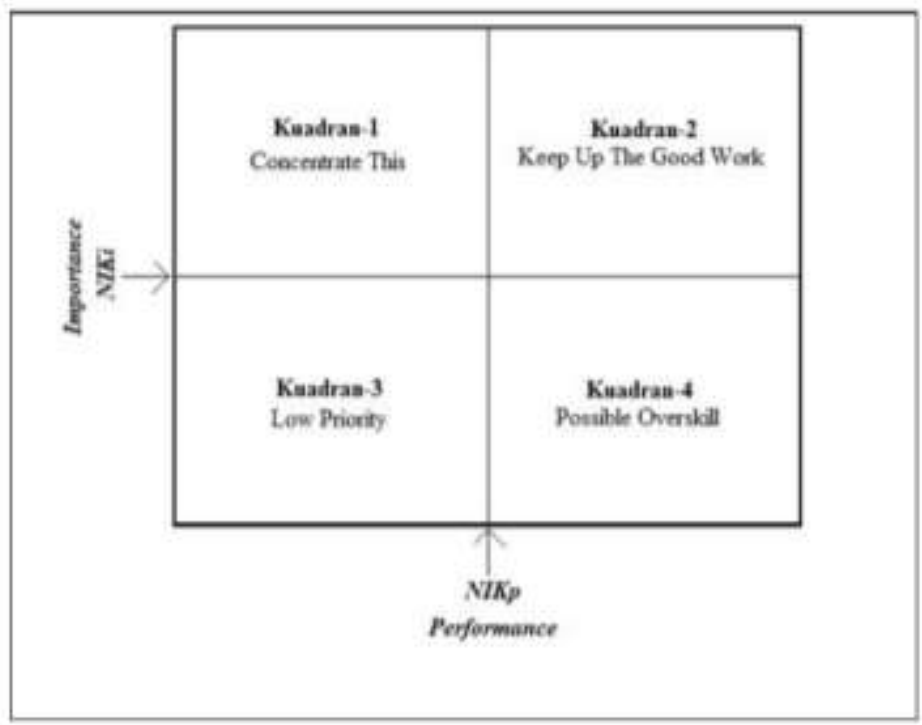

Gambar 1. Importance-Performance Matrix Framework 
Dalam metode Importance-Performance Matrix ini terdapat empat kuadran yang mempresentasikan kondisi sebagai berikut [6] [7]:

1. Kuadran I, Perusahaan disarankan harus meningkatkan kinerja karena pelanggan memiliki ekspektasi tinggi pada atribut pada kuadran ini.

2. Kuadran II, perusahaan harus mempertahankan prestasi karena perusahaan dianggap telah menunjukkan kinerja yang baik pada atribut yang dinilai penting/harus ada oleh pelanggan.

3. Kuadran III, kuadran ini merupakan kuadran yang memuat atribut layanan yang tidak penting/tidak harus ada oleh pelanggan sehingga perusahaan juga dapat mendefinisikan atribut ke dalam kelompok low priority.

4. Kuadran IV, kuadran ini merupakan kuadran yang berisi atribut tidak penting/tidak wajib oleh pelanggan, namun demikian kinerja perusahaan sudah baik dalam pelayanan.

\section{Metode Penelitian}

Metode penelitian yang diimplementasikan merupakan serangkaian langkah yang dilakukan dalam menjalankan penelitian terhadap evaluasi pelayanan pada "ABC" care cleaners, detail penjelasan akan diuraikan dalam Gambar 2 [8] [9].

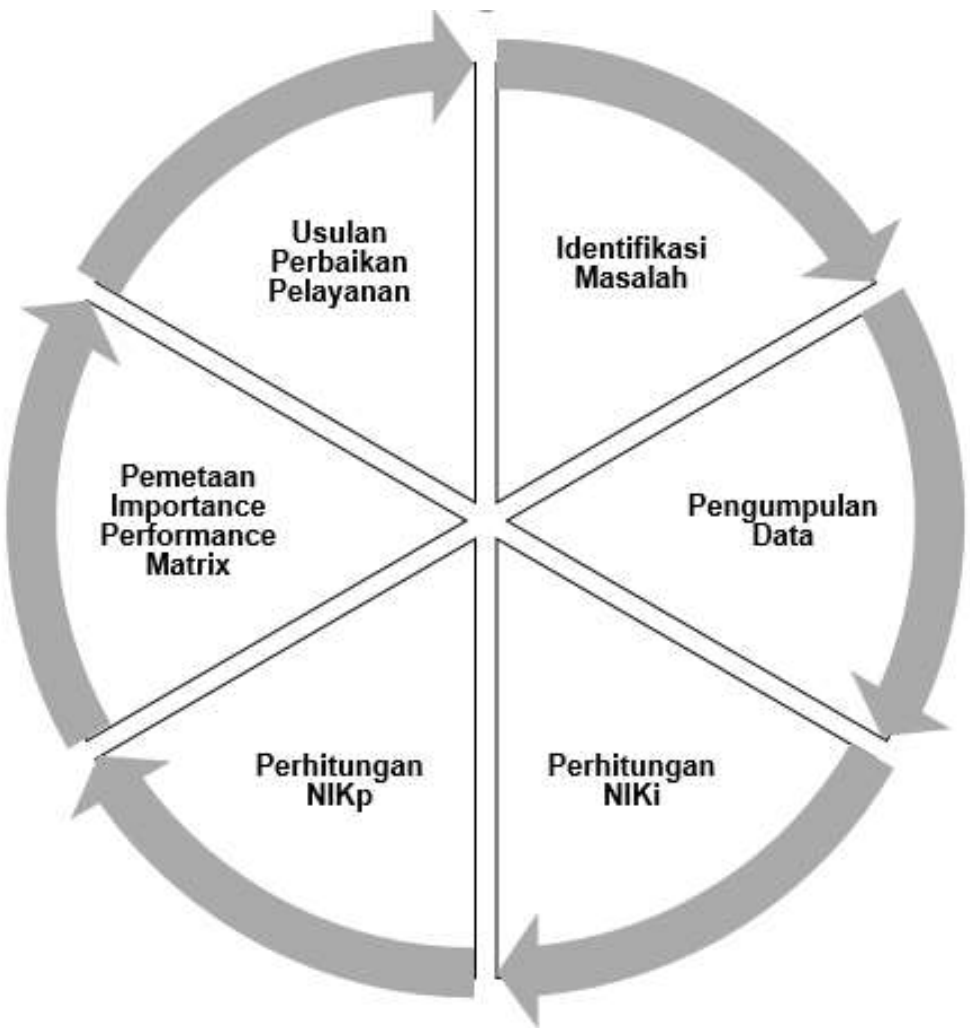

Gambar 2. Metode Penelitian Importance-Performance Matrix

\subsection{Identifikasi Masalah}

Tahapan identifikasi masalah merupakan step pertama yang diambil dalam penelitian, dalam tahap ini peneliti menganalisis permasalahan yang ada pada "ABC" care cleaners dalam pelayanan yang diberikan kepada pelanggan. Setelah masalah teridentifikasi, maka kemudian akan dianalisis dan ditentukan atribut-atribut yang berpengaruh terhadap kualitas layanan tersebut.

\subsection{Pengumpulan Data}

Pengumpulan data untuk penelitian berupa wawancara terhadap pihak manajemen "ABC" care cleaners, materi wawancara terkait pelayanan sesuai dimensi utama dalam kualitas jasa. Misalnya, kenyamanan ruang tunggu, kenyamanan tempat parkir, kerapian penampilan karyawan dalam memberikan pelayanan, kerapian hasil setrika dan pelipatan pakaian, kecekatan karyawan dalam menanggapi keluhan pelanggan, jaminan bahwa pakaian tidak akan tertukar atau rusak, dan kecepatan dan ketepatan dalam estimasi pencucian dan penyetrikaan. 


\subsection{Perhitungan NIKi}

NIK merupakan singkatan dari Nilai Indeks Kinerja yang nantinya akan di bagi menjadi Nilai Indeks Kinerja Tingkat Kepentingan (NIKi) dan Nilai Indeks Kinerja Tingkat Kepuasan (NIKp). Nilai Indeks Kinerja ini merupakan tahapan yang dilakukan sebelum posisi variabel kualitas jasa.

Rata-rata skor tingkat kepentingan (NIKi) seluruh variabel atau atribut terhadap tingkat kepuasan dapat dijabarkan dalam Persamaan 1.

$$
N I K_{i}=\frac{\sum\left(N_{j} \cdot X_{i}\right)}{\sum k}
$$

\subsection{Perhitungan NIKp}

Sedangkan rata-rata skor tingkat performa atau kinerja perusahaan (NIKp) variabel atau atribut yang berpengaruh terhadap tingkat kepuasan dapat dijabarkan dalam Persamaan 2.

$$
N I K_{p}=\frac{\sum\left(N_{j} \cdot X_{i}\right)}{\sum k}
$$

\subsection{Pemetaan Importance Performance Matrix}

Setelah diperoleh nilai masing-masing Nilai Indeks Kinerja untuk tingkat kepuasan dan tingkat performa, maka kemudian dibuat diagram kartesius untuk pemetaan ImportancePerformance Matrix dengan menggunakan nilai rata-rata NIKi sebagai pembagi pada sumbu $Y$ dan nilai rata-rata NIKp sebagai pembagi sumbu $X$ [10]. Uraian rumusnya terurai pada Persamaan 3 dan Persamaan 4.

$$
\begin{gathered}
\overline{N I K_{i}}=\frac{\sum N I K_{i}}{Y} \\
\overline{N I K_{p}}=\frac{\sum N I K_{p}}{Y}
\end{gathered}
$$

\subsection{Usulan Perbaikan Layanan}

Usulan perbaikan layanan atau perbaikan kinerja perusahaan dapat di berikan setelah hasil dari pemetaan Importance-Performance Matrix dilakukan. Dari pemetaan tersebut akan diperoleh variabel atau atribut apa saja yang berada pada kuadran I. Maka pelayanan atau kinerja itulah yang harus di tingkatkan oleh perusahaan.

\section{Hasil Penelitian dan Pembahasan}

Pembahasan penelitian ini dimulai dari analisa hasil kuesioner yang telah disebar kepada pelanggan, dengan sampel 100 responden dan 45 variabel atau atribut dalam kuesioner tersebut. Setelah dilakukan validasi dan reabilitas terhadap data, kemudian akan dilakukan perhitungan data berdasarkan Nilai Indeks Kinerja. Uraian analisa dan perhitungan data kuesioner akan dijelaskan pada sub bab berikut.

\subsection{Perhitungan Nilai Indeks Kinerja (NIK)}

Dari 45 variabel yang telah diuji pada kuesioner dengan total 100 responden, kemudian dilakukan perhitungan Nilai Indeks Kinerja tingkat kepentingan suatu variabel atau atribut. Skala likert yang digunakan dalam kuesioner berjumlah 4 skala likert, yaitu:

$\begin{array}{llll}\text { STP } & \text { : Sangat Tidak Penting } & \text { Nilai } & : 1 \\ \text { TP } & \text { : Tidak Penting } & \text { Nilai } & : 2 \\ \text { P } & \text { : Penting } & \text { Nilai } & : 3 \\ \text { SP } & \text { : Sangat Penting } & \text { Nilai } & : 4\end{array}$

Dari perhitungan yang telah dilakukan pada setiap variabel yang telah ditentukan, diperoleh rata-rata Nilai Indeks Kinerja tingkat kepentingan adalah 3.34. untuk nilai masingmasing variabel dapat dilihat pada Tabel 1. 


\begin{tabular}{|c|c|c|c|c|c|c|}
\hline \multirow{2}{*}{ Variabel } & STP & TP & $P$ & SP & \multirow[b]{2}{*}{$\mathrm{NIKi}$} & \multirow{2}{*}{$\begin{array}{c}\text { Rata2 } \\
\text { NIKi }\end{array}$} \\
\hline & 1 & 2 & 3 & 4 & & \\
\hline 1 & & & 35 & 65 & 3.65 & \\
\hline 2 & & & 30 & 70 & 3.7 & \\
\hline 3 & & & 20 & 80 & 3.8 & \\
\hline 4 & & & 28 & 72 & 3.72 & \\
\hline 5 & & & 14 & 86 & 3.86 & \\
\hline 6 & & 3 & 26 & 71 & 3.68 & \\
\hline 7 & & 2 & 18 & 80 & 3.78 & \\
\hline 8 & 1 & 2 & 38 & 59 & 3.55 & \\
\hline 9 & 3 & 7 & 25 & 65 & 3.52 & \\
\hline 10 & 56 & 13 & 23 & 8 & 1.83 & \\
\hline 11 & 9 & 20 & 48 & 23 & 2.85 & \\
\hline 12 & & 21 & 30 & 49 & 3.28 & \\
\hline 13 & & 10 & 30 & 60 & 3.5 & \\
\hline 14 & & & 29 & 71 & 3.71 & \\
\hline 15 & & & 11 & 89 & 3.89 & \\
\hline 16 & & 2 & 40 & 58 & 3.56 & \\
\hline 17 & & 17 & 37 & 46 & 3.29 & \\
\hline 18 & 6 & 9 & 35 & 50 & 3.29 & \\
\hline 19 & & 5 & 30 & 65 & 3.6 & \\
\hline 20 & & 2 & 62 & 36 & 3.34 & \\
\hline 21 & & 2 & 65 & 33 & 3.31 & \\
\hline 22 & & 4 & 29 & 67 & 3.63 & \\
\hline 23 & 2 & 11 & 56 & 31 & 3.16 & 3.34 \\
\hline 24 & & 14 & 59 & 27 & 3.13 & \\
\hline 25 & & 5 & 41 & 54 & 3.49 & \\
\hline 26 & 7 & 51 & 27 & 15 & 2.5 & \\
\hline 27 & 4 & 4 & 14 & 78 & 3.66 & \\
\hline 28 & 3 & 6 & 28 & 63 & 3.51 & \\
\hline 29 & 4 & 12 & 35 & 49 & 3.29 & \\
\hline 30 & 4 & 4 & 32 & 60 & 3.48 & \\
\hline 31 & 4 & 10 & 60 & 26 & 3.08 & \\
\hline 32 & 9 & 50 & 26 & 15 & 2.47 & \\
\hline 33 & 7 & 6 & 70 & 17 & 2.97 & \\
\hline 34 & 3 & 8 & 57 & 32 & 3.18 & \\
\hline 35 & & & 29 & 71 & 3.71 & \\
\hline 36 & & & 44 & 56 & 3.56 & \\
\hline 37 & & 1 & 60 & 39 & 3.38 & \\
\hline 38 & 10 & 21 & 50 & 19 & 2.78 & \\
\hline 39 & & & 40 & 60 & 3.6 & \\
\hline 40 & & 5 & 54 & 41 & 3.36 & \\
\hline 41 & & 1 & 65 & 34 & 3.33 & \\
\hline 42 & & 4 & 68 & 28 & 3.24 & \\
\hline 43 & 17 & 50 & 23 & 10 & 2.26 & \\
\hline 44 & & 9 & 51 & 40 & 3.31 & \\
\hline 45 & & 3 & 37 & 60 & 3.57 & \\
\hline
\end{tabular}

Sedangkan untuk kuesioner pengaruh variabel atau atribut pada Nilai Indeks Kinerja tingkat kepuasan juga terdapat 4 skala likert, yaitu:

$\begin{array}{llrl}\text { STP } & \text { : Sangat Tidak Puas } & \text { Nilai } & : 1 \\ \text { TP } & \text { : Tidak Puas } & \text { Nilai } & : 2 \\ \text { P } & \text { : Puas } & \text { Nilai } & : 3 \\ \text { SP } & \text { : Sangat Puas } & \text { Nilai } & : 4\end{array}$


Hasil yang diperoleh dari perhitungan masing-masing variabel dapat dilihat pada Tabel 2. Sedangkan untuk nilai rata-rata Nilai Indeks Kinerja tingkat kepuasan diperoleh nilai 3.16.

Tabel 2. NIK Tingkat Kepuasan

\begin{tabular}{|c|c|c|c|c|c|c|}
\hline \multirow{2}{*}{ Variabel } & STP & TP & $\mathrm{P}$ & SP & \multirow{2}{*}{ NIKp } & \multirow{2}{*}{$\begin{array}{l}\text { Rata- } \\
\text { rata } \\
\text { NIKp }\end{array}$} \\
\hline & 1 & 2 & 3 & 4 & & \\
\hline 1 & 2 & 30 & 50 & 18 & 2.84 & \\
\hline 2 & 1 & 12 & 62 & 25 & 3.11 & \\
\hline 3 & & 3 & 68 & 29 & 3.26 & \\
\hline 4 & 2 & 21 & 56 & 21 & 2.96 & \\
\hline 5 & & 1 & 69 & 30 & 3.29 & \\
\hline 6 & 3 & 8 & 48 & 41 & 3.27 & \\
\hline 7 & & 5 & 60 & 35 & 3.3 & \\
\hline 8 & 3 & 9 & 58 & 30 & 3.15 & \\
\hline 9 & & 5 & 50 & 45 & 3.4 & \\
\hline 10 & 2 & 13 & 69 & 16 & 2.99 & \\
\hline 11 & & 10 & 58 & 32 & 3.22 & \\
\hline 12 & & 15 & 47 & 38 & 3.23 & \\
\hline 13 & & 10 & 50 & 40 & 3.3 & \\
\hline 14 & & 10 & 52 & 38 & 3.28 & \\
\hline 15 & & 11 & 58 & 31 & 3.2 & \\
\hline 16 & 9 & 20 & 53 & 18 & 2.8 & \\
\hline 17 & & 16 & 47 & 37 & 3.21 & \\
\hline 18 & & 12 & 51 & 37 & 3.25 & \\
\hline 19 & & 11 & 49 & 40 & 3.29 & \\
\hline 20 & & 9 & 46 & 45 & 3.36 & \\
\hline 21 & & 4 & 59 & 37 & 3.33 & \\
\hline 22 & 2 & 20 & 50 & 28 & 3.04 & \\
\hline 23 & & 5 & 50 & 45 & 3.4 & 3.16 \\
\hline 24 & & 17 & 60 & 23 & 3.06 & \\
\hline 25 & 3 & 55 & 32 & 10 & 2.49 & \\
\hline 26 & 7 & 51 & 27 & 15 & 2.5 & \\
\hline 27 & & 5 & 20 & 75 & 3.7 & \\
\hline 28 & 3 & 11 & 48 & 38 & 3.21 & \\
\hline 29 & & 1 & 50 & 49 & 3.48 & \\
\hline 30 & & 10 & 40 & 50 & 3.4 & \\
\hline 31 & & 5 & 42 & 53 & 3.48 & \\
\hline 32 & 2 & 60 & 23 & 15 & 2.51 & \\
\hline 33 & 9 & 20 & 48 & 23 & 2.85 & \\
\hline 34 & & 2 & 43 & 55 & 3.53 & \\
\hline 35 & & 8 & 47 & 45 & 3.37 & \\
\hline 36 & 1 & 10 & 48 & 41 & 3.29 & \\
\hline 37 & 4 & 27 & 49 & 20 & 2.85 & \\
\hline 38 & & 21 & 50 & 29 & 3.08 & \\
\hline 39 & & 4 & 26 & 70 & 3.66 & \\
\hline 40 & & 18 & 42 & 40 & 3.22 & \\
\hline 41 & 1 & 1 & 47 & 51 & 3.48 & \\
\hline 42 & 1 & 5 & 46 & 48 & 3.41 & \\
\hline 43 & 23 & 35 & 30 & 12 & 2.31 & \\
\hline 44 & 6 & 10 & 41 & 43 & 3.21 & \\
\hline 45 & 9 & 30 & 40 & 21 & 2.73 & \\
\hline
\end{tabular}

\subsection{Pemetaan Variabel Melalui Importance Performance Matrix}

Pemetaan variabel yang berpengaruh terhadap tingkat kepuasan dan tingkat kepentingan dapat dilakukan jika telah diperoleh hasil dari perhitungan masing-masing variabel beserta rata-rata nilai indeks kinerjanya. Pemetaan ini digambarkan dalam diagram kartesius

KINETIK Vol. 2, No. 3, Agustus 2017: 235-242 
yang terdiri dari empat kuadran. Nilai rata-rata NIKi nantinya akan digunakan sebagai garis pembatas kuadran yang saling berpotongan pada sumbu $Y$, sedangkan garis pembatas kuadran pada sumbu $X$ merupakan nilai rata-rata NIKp. Hasil pemetaan masing-masing variabel dapat dilihat pada Gambar 3.

Importance Performance Matrix

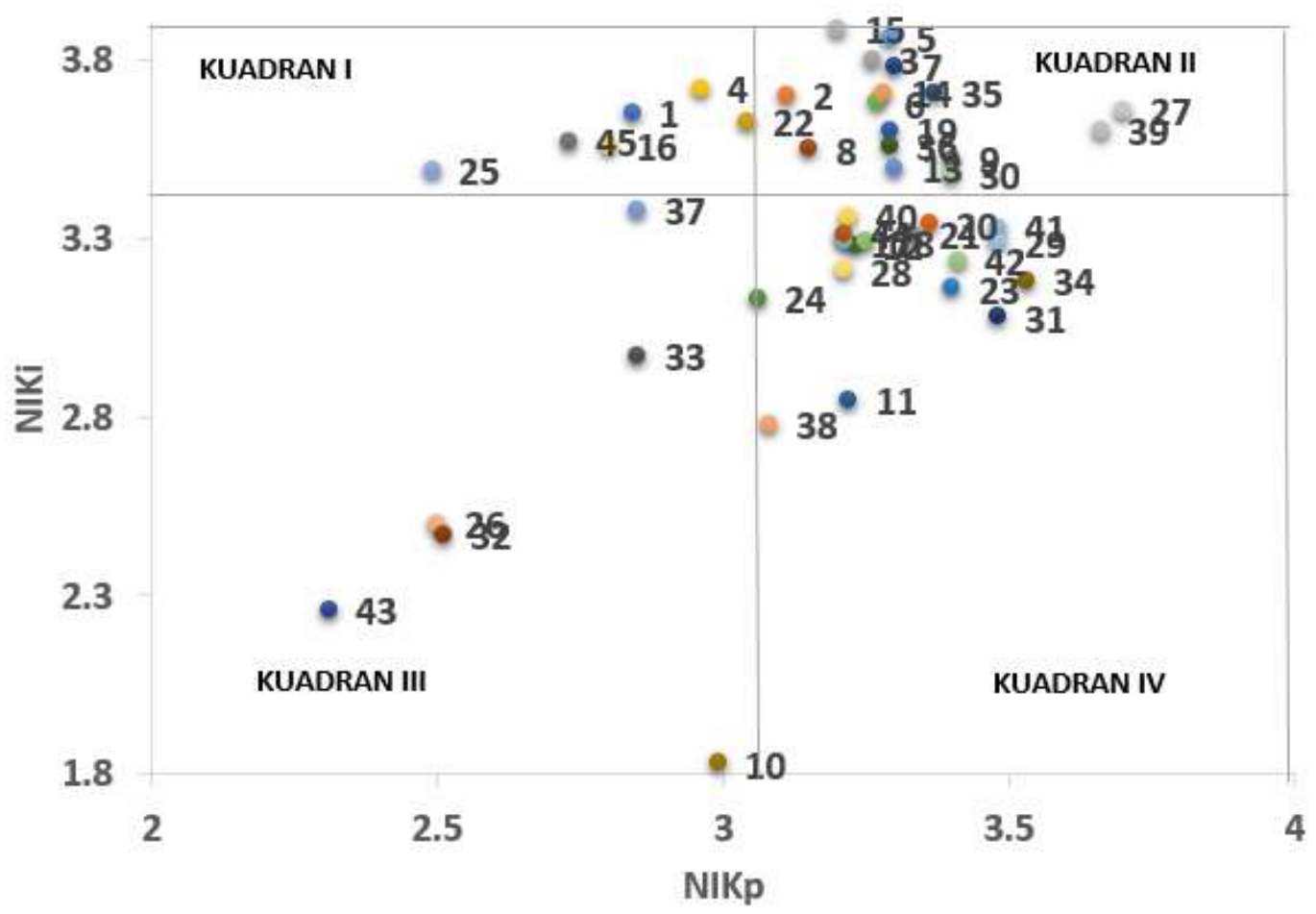

Gambar 3. Pemetaan Variabel Menggunakan Importance Performance Matrix

Dari perhitungan yang telah dilakukan dapat diketahui bahwa nilai rata-rata NIKi (importance) lebih tinggi dari pada nilai rata-rata NIKp (performance), yaitu 3.34 dan 3.16. Hal ini menunjukkan bahwa masih ada beberapa kinerja atau pelayanan perusahaan yang di rasa kurang maksimal oleh pelanggan.

\subsection{Usulan Perbaikan dan Peningkatan Kualitas Layanan}

Usulan perbaikan untuk "ABC" care cleaners akan dilihat dari prioritas ketidakpuasan pelanggan pada pelayanan perusahaan. Hal ini dapat diperoleh dari perkalian nilai NIKi masingmasing variabel yang masuk pada kuadran I dengan nilai NIKp masing-masing variabel yang masuk pada kuadran I. hasil perkalian tersebut akan menentukan tingkat prioritas variabel pelayanan yang harus diperbaiki dan ditingkatkan (Tabel 3 ).

Tabel 3. Usulan Perbaikan dan Peningkatan Pelayanan

\begin{tabular}{clcc}
\hline Variabel & \multicolumn{1}{c}{ Uraian Variabel } & NIKi x NIKp & Prioritas \\
\hline 22 & $\begin{array}{l}\text { Pakaian yang sudah di cuci diberikan tempat } \\
\text { khusus }\end{array}$ & 11.04 & 1 \\
\hline 4 & Warna pakaian tidak pudar setelah dicuci & 11.01 & 2 \\
\hline 1 & $\begin{array}{l}\text { Tidak ada noda tertinggal pada pakaian yang } \\
\text { telah di cuci }\end{array}$ & 10.37 & 3 \\
\hline 16 & $\begin{array}{l}\text { tempat meletakkan pakaian yang telah di cuci } \\
\text { terjaga kebersihannya }\end{array}$ & 9.97 & 4 \\
\hline 45 & $\begin{array}{l}\text { Karyawan cekatan dalam menangani keluhan } \\
\text { dan permasalahan pelanggan }\end{array}$ & 9.75 & 5 \\
\hline 25 & Tersedia tempat parkir yang luas & 8.69 & 6 \\
\hline
\end{tabular}




\section{Kesimpulan}

Berdasarkan analisa pengolahan hasil kuesioner pada 100 orang responden dengan jumlah 45 variabel, diperoleh nilai NIKi (importance) adalah sebesar 3.34 dan nilai NIKp (performance) sebesar 3.16. Hal ini menunjukkan bahwa ekspektasi pelanggan masih diatas kinerja/performa pelayanan perusahaan, sehingga harus ada perbaikan dan peningkatan pada beberapa variabel yang saling berpengaruh terhadap performa pelayanan. Dari hasil pemetaan diagram kartesius Importance-Performance Matrix, diperoleh 6 variabel yang harus ditingkatkan kualitasnya pada "ABC" care cleaners. Adapun usulan perbaikan dan peningkatan sesuai hasil penelitian adalah menyediakan tempat tersendiri untuk baju/pakaian yang sudah di cuci bersih dan menunggu proses setrika, mengkaji ulang proses pencucian agar warna tidak pudar setelah pakaian dicuci, mengkaji ulang kuantitas dan estimasi waktu pencucian sehingga tidak ada noda lagi yang tertinggal di baju, menyediakan raung khusus yang terjaga kebersihannya untuk pakaian/barang yang telah di cuci, memberikan pelatihan berkala kepada karyawan terkait pelayanan prima dan penanganan keluhan, serta menambah kapasitas lahan parkir agar pelanggan lebih nyaman. Untuk penelitian selanjutnya, akan dibuat analisa kinerja dengan metode berbeda sehingga akan ada perbandingan metode yang lebih akurat/bagus untuk menganalisis dan mengukur kinerja perusahaan dalam pelayanan ke customer.

\section{Daftar Notasi}

Berikut adalah daftar notasi yang digunakan dalam penelitian Importance-Performance Matrix pada "ABC" care cleaners:

Niki : Nilai Indeks Kinerja pada variabel ke-i

NIKp : Nilai Indeks Kinerja pada variabel ke-i

$\mathrm{Nj} \quad$ : Skor skala likert yang dipilih oleh responden

$\mathrm{Xi} \quad$ : Jumlah responden yang memilih skala sikap

$\mathrm{k} \quad$ : jumlah total responden

Y : jumlah variabel pada kuesioner

\section{Referensi}

[1] K. Kardoyo, A. Nurkhin, "Analisis Kepuasan Pelayanan Perguruan Tinggi (Kasus pada Prodi Magister Pendidikan Ekonomi Unnes)," Jurnal Cakrawala Pendidikan, Vol. 15, No. 2, Pp. 164-175, 2016.

[2] H. Pijoh, L. Lambey, "The Importance-Performance Analysis of Service Quality At Aquarius Car Wash," Jurnal Riset Ekonomi Manajemen, Bisnis dan Akuntansi, Vol. 4, No. 2, Pp. 475484, 2016.

[3] A. Suhendra, D. Prasetyanto, "Kajian Tingkat Kepuasan Pengguna Trans Metro Bandung Koridor 2 Menggunakan Pendekatan Importance-Performance Analysis," REKA RACANA, Vol. 2, No. 2, Pp. 1-12, 2016.

[4] A. Buchari, "Manajemen Pemasaran dan Pemasaran Jasa," Edisi 2., Bandung: Alfabeta, 2003.

[5] M. Utama, A. Harsono, D. Novirani, "Usulan Peningkatan Kepuasan Layanan Dengan Metode Importance Performance Matrix (IPM) (Studi Kasus Poliklinik Kebidanan dan Kandungan RSUP Dr. Hasan Sadikin Bandung)," REKA INTEGRA, Vol. 2, No. 4, Pp. 377388, 2014.

[6] L. Noer, "Analisis Peningkatan Kualitas Pelayanan Mahasiswa Magister Manajemen Teknologi Its Surabaya Dengan Metode Servqual dan Importance Performance Analisys (IPA)," Journal of Researh and Technologies, Vol. 2, No. 1, Pp. 35-43, 2016.

[7] S. DESTRIANI, H. Rukmi, S. Susanty, "Usulan Perbaikan Kualitas Pelayanan Minimarket Intimart Dengan Menggunakan Metode Importance Performance Matrix," REKA INTEGRA, Vol. 1, No. 4, Pp. 259-268, 2013.

[8] H. Nawawi, Metode penelitian bidang sosial. Yogyakarta: Gajah Mada University Press, 1995.

[9] C. Wahyuni, Y. Yuniar, A. Desrianty, "Usulan Perbaikan dan Peningkatan Kualitas Jasa Pelayanan Taman Bacaan Menggunakan Metode Importance Performance Matrix," REKA INTEGRA, Vol. 2, No. 2, Pp. 157-166, 2014.

[10] D. Darmadi, M. Arifin, I. Agustin, "Kajian Tingkat Kepuasan Pengguna Jasa terhadap Kinerja Pelayanan Angkutan Penyeberangan Lintas Kariangau-Penajam, Balikpapan," Media Teknik Sipil, Vol. 14, No. 1, Pp. 42-50, 2016. 